\title{
ARTE y Política: Las INTERVENCIONES Públicas del Frente CULtURAL "MARÍA ReMEDIOS DEL VALLE" (AvelLANEDA, 2018-2019)
}

\author{
Valeria Lucia Saponara Spinetta \\ CONICET/UNDAV y UBA, Buenos Aires, Argentina ${ }^{1}$
}

El Frente Cultural "María Remedios del Valle" es un colectivo de artistas militantes de la ciudad de Avellaneda conformado en 2018. El colectivo se presenta como base de apoyo de las gestiones kirchneristas en relación a las elecciones 2019 y se opone a las gestiones de cambiemos y sus politicas. El propósito del articulo es analizar la acción colectiva y militante que asume el Frente Cultural, focalizando en las reivindicaciones y en las intervenciones artístico-culturales-entendidas en términos de performance- que realizó en el espacio público y virtual, entre junio de 2018 y agosto de 2019. Realicé trabajo de campo. Entrevisté a militantes, adherentes del Frente y a trabajadores de la gestión; y realicé observación participante en actividades del colectivo y en las redes sociales que utiliza. En el actual contexto de crisis social es de interés visualizar la acción colectiva de los actores hacia las politicas que los afectan.

Palabras clave: acción colectiva, militancia, intervenciones públicas, performance, artistas

La ciudad de Avellaneda (zona sur del conurbano bonaerense, Buenos Aires, Argentina), se destaca desde mediados del siglo XX por su variada oferta cultural (Ferreño y Giménez 2019). Actualmente, la gestión municipal -responde desde 2009 al Frente para la Victoria-2 se distingue por la amplia oferta cultural y educativa, por promover la participación ciudadana y propiciar acciones de resistencia hacía Cambiemos. ${ }^{3}$ Sobresalen los ocho Institutos de

1 CONICET, Universidad Nacional de Avellaneda (Departamento de Humanidades y Artes) y UBA (Facultad de Ciencias Sociales). Versiones preliminares de este artículo fueron presentadas en las Terceras Jornadas de Investigación: Cuerpo, Arte y Comunicación de la Universidad Nacional de la Plata y en las II Jornadas de Sociología de la Universidad Nacional de Mar del Plata. Contacto de la autora: valeria.spinetta@conicet.gov.ar 2 El Frente para la Victoria $(\mathrm{FpV})$ fue una coalición política argentina de orientación peronista fundada en 2003 para sostener la candidatura presidencial de Néstor Kirchner. En 2007 y 2011 sostuvo la de Cristina Fernández y en 2015 la de Daniel Scioli. En 2017 formó la coalición Unidad Ciudadana -liderada por Cristina Fernández-; y en 2019 convergió en la coalición política Frente de Todxs -liderada junto a Alberto Fernández-.

3 El partido político reconocido legalmente en 2005 como Compromiso para el Cambio, pasó a llamarse Propuesta Republicana (Pro) en 2008. En 2015 se unió a la Unión Cívica Radical y a la Coalición Cívica ARI, 
Formación Artística y Pedagógica y entidades de educación como el Programa Punto Cultural -que brinda talleres gratuitos de formación y recreación en los barrios-.

Actores vinculados con espacios y grupos culturales y militantes de la ciudad conformaron -en junio de 2018- el Frente Cultural "María Remedios del Valle", ${ }^{4}$ con sede en el Centro Cultural Alas del Sur ${ }^{5}$. El origen del colectivo se sitúa en el tercer año de la gestión del Frente Cambiemos, signado, a nivel local, por la disminución del aporte provincial para los Institutos Municipales de Enseñanza Artística, la suba de las tarifas y la intensificación de la protesta social. El colectivo se presenta como "una organización política y cultural que reivindica un modelo cultural nacional y popular enfrentado al neoliberal del macrismo" [documento oficial]. El surgimiento del Frente se ubica en un contexto marcado -a nivel regional y nacional- por el pasaje de gobiernos populares -identificados como "progresistas" o "anti-neoliberales", de izquierda o centro-izquierda- ${ }^{6}$ a otros de centro derecha -identificados como neoliberales-. ${ }^{7}$ Según Yúdice, el dominio actual del neoliberalismo comprende:

el conjunto de políticas que incluye la liberalización comercial, la privatización, la reducción (y en algunos casos la eliminación) de los servicios subsidiados por el Estado, tales como el cuidado de la salud y la educación, los recortes salariales y el aniquilamiento de los derechos laborales. (Yúdice 2002: 18)

Considero que el actual contexto de crisis social -y la crítica de la que es objeto- propició la apertura de diferentes formas de resistencia, y que, en el caso particular del Frente, actuó como principio de identificación promoviendo la movilización política y el ingreso a la militancia de personas enfrentadas a las gestiones de cambiemos y sus políticas. El propósito de este artículo es analizar la acción colectiva y militante que asume el Frente Cultural, atendiendo a las intervenciones artístico-culturales -entendidas como performance- que el colectivo realizó en el espacio público y virtual, ${ }^{8}$ y a las reivindicaciones que expresó, entre junio de 2018 y agosto de 2019.

formando el Frente Cambiemos. En diciembre de 2015, mediante un discurso que apelaba al cambio -con respecto al modelo anterior- y promesas de achicar el Estado, iniciaron sus mandatos Mauricio Macri (a nivel nacional) y María Eugenia Vidal (por la provincia de Buenos Aires). En 2019, surgió una nueva coalición electoral: Juntos por el Cambio -con Mauricio Macri y María Eugenia Vidal como candidatos a presiente y a gobernadora de la Provincia de Buenos Aires-. En términos coloquiales se lo nombra cambiemos o macrismo.

4 En referencia a la militar afrodescendiente argentina reconocida con el grado de oficial en las Guerras de Independencia. Su figura es exaltada mediante manifestaciones públicas del Frente, allí se la presenta como "defensora de nuestra soberanía", "Capitana del ejército de Belgrano" y "Madre de la Patria".

5 Inaugurado en 2011, reviste carácter de asociación civil autogestionada -aunque cuenta con financiamiento municipal-, cuyo objetivo es "promover la inclusión mediante distintas actividades que estimulen la participación de la comunidad usando como herramientas la educación y la cultura popular" [documento oficial]. Es sede de un Punto Cultural.

6 En el caso argentino, los gobiernos de Néstor Kirchner (2003-2007) y Cristina Fernández (2007-2011; 2011-2015) presentaron logros en materia de ampliación de derechos. Pero, pese al discurso anti-neoliberal que apeló a los derechos humanos, la justicia social y la redistribución de la riqueza, no se lograron grandes avances en materia estructural con respecto a combatir la desigualdad.

7 Las gestiones de gobierno que asumieron en diciembre de 2015 redujeron las funciones del Estado en materia de derechos, políticas públicas y gasto público, y evidenciaron un cambio, con respecto al modelo anterior, en la manera de conceptualizar el rol del Estado frente a la cultura.

8 Entiendo que el espacio no es algo dado sino que está siempre siendo construido e imaginado. Según Gupta y Ferguson (2008), en el espacio pulverizado de la posmodernidad, el espacio ha sido re-territorializado lo cual implica la emergencia de nuevas formas de experiencias. Las intervenciones, que el Frente realiza en el espacio, serán concebidas como móviles. 
Analizaré el carácter político del Frente Cultural (Bonvilliani y otros 2010) y concebiré a la militancia como proceso (Fillieule 2015), teniendo en cuenta el paso a la acción, la predisposición a la militancia y los momentos de interés en la acción militante. Me serviré de la perspectiva de Becker (2008) para analizar el arte -y la militancia política- como una actividad humana que implica la acción conjunta de personas que cooperan -aunque no sin conflicto-. E1 concepto "militancia de la gestión" (Vázquez 2014), me permitirá vincular las experiencias de participación de los/las integrantes del Frente con el área estatal donde se desempeñan laboralmente, y observar las tensiones que ese relación conlleva. Por su parte, el concepto de "campo arte-transformador" (Infantino 2019a) resulta útil para pensar las prácticas artísticas colectivas del Frente, dado que sus integrantes postulan al arte como estrategia para la transformación social. Como retoma Avenburg (2012), la performance será abordada como formas de expresar, interpretar, recrear y crear experiencias (Turner 1982).

Para cumplir los objetivos propuestos realicé trabajo de campo: entrevisté a militantes del Frente, a trabajadores/as de la gestión -quienes, en su mayoría, integran el Frente- y a adherentes del colectivo -quienes participan en actividades del Frente de forma regular y/o ocasional-; y realicé observación participante en sus actividades y en las redes sociales que utiliza (Facebook, Instagram y Whats $A p p$ ). ${ }^{9} \mathrm{~A}$ su vez, recolecté y analicé fuentes secundarias (documentos oficiales y periodísticos). De este modo, me propuse acceder a las narrativas y prácticas para reconstruir las experiencias de participación, dado que considero interesante visualizar la respuesta pública de los actores sociales hacía las políticas que los afectan.

\section{LA ACCIÓN COLECTIVA DEL FRENTE CULTURAL}

E1 Frente se presenta como base de apoyo de las gestiones kirchneristas en relación a las elecciones 2019. Según expresó un integrante [entrevista personal, diciembre 2018]: "pensamos hacer un gran frente que se ponga a trabajar para la campaña". ${ }^{10}$ Aunque provienen de diferentes orientaciones políticas, sus miembros coinciden en oponerse a las gestiones y políticas de cambiemos; de este modo, desde la organización interna del Frente se comprende que [entrevistas personales a militantes, septiembre 2018]: "lo que unió fue el ir en contra de Macri"; "la iniciativa nace a raíz de las políticas empleadas por este gobierno de turno. En defensa de la cultura". Según expresan públicamente sus integrantes [Radio Cítrica, 02/07/2018]: "buscamos resistir a los avances neoliberales". Para infantino (2019b), las demandas colectivas y reivindicativas que fueron habilitadas en contextos políticos-ideológicos vinculados con políticas democrático-participativas, se encuentran resistiendo frente a procesos de pauperización. Según la autora:

La agudización de los índices de pobreza, el endeudamiento de las economías nacionales, la disminución de los salarios frente a devaluaciones de la moneda interna, el estancamiento del consumo, entre otras, son situaciones que agravan el escenario en el que accionan las propues-

9 Entablé relación con integrantes de la Dirección de Cultura municipal por intermedio de un colectivo de músicos militantes de Avellaneda (UMA), al cual vengo investigando desde el año 2016. A través de este vínculo fui invitada a participar en actividades del área de cultura municipal y del Frente Cultural. Desde entonces, he realizado observación participante posicionándome como investigadora y a la vez música, lo cual ha requerido un esfuerzo mayor a la hora de tomar distancia objetiva para realizar mi investigación.

10 El entrecomillado se utilizará para citar discurso directo, términos o expresiones nativas y para destacar o enfatizar una idea y las itálicas se usaran para referir palabras extranjeras. 
tas que desde las artes pretenden garantizar acceso a derechos y transformar la sociedad hacia mayores niveles de justicia social. (Infantino 2019b: 54)

Entiendo por valores a los "«modos de comportamiento" o «estados de existencia», percibidos como algo que «valdría la pena ser protegido o promovido» (Cefaï 2008: 52). En tal sentido, el Frente enfatiza valores considerados opuestos a los del macrismo como "la justicia social, el asociativismo, la solidaridad, la integración social, la politización, el nacionalismo y latinoamericanismo" [documento oficial], y postula que:

El macrismo busca, a través de sus dispositivos de difusión (redes sociales, medios oficiales, conglomerados de medios privados, etc.) que el pueblo naturalice las atrocidades que están cometiendo en términos de derechos humanos y sociales. A su vez, intenta instalar en la sociedad un sistema de valores y símbolos que haga las veces de "lubricante" para que su modelo económico obtenga el consenso mayoritario de la población [documento oficial].

Según Becker (2009:15), "la gente que se involucra en una acción colectiva define aquello que es «malo» y que no debe hacerse, y en general da los pasos necesarios para evitar que se realice ese tipo de acciones”. En este sentido, los/las militantes del Frente asumen una acción colectiva, realizan intervenciones artístico-culturales -públicas y políticas- con el objetivo de generar adhesión política, reclutamiento militante y oposición hacía cambiemos; a fin de incidir en la definición de las elecciones. Así, las políticas del macrismo son percibidas como neoliberales y como un problema por quienes integran el Frente y, a la vez, actúan promoviendo el vínculo generacional del colectivo, que elabora la necesidad de superarlas mediante prácticas colectivas.

Considero que el Frente Cultural -y sus prácticas- tiene carácter político ya que expresa los cuatro aspectos que destacan Bonvilliani, Palermo, Vázquez y Vommaro (2010). En tal sentido, el Frente supera lo individual y se produce a partir de una organización colectiva; adquiere visibilidad pública (sus integrantes, acciones y demandas se dirimen en el espacio público); expresa un conflicto (reconoce un antagonista a partir del cual la organización adquiere potencial político); y formula demandas y reclamos que adquieren un carácter público y contencioso. La acción colectiva del Frente tiene sentido político ya que "es asumida como la capacidad de afectar y participar en una construcción social” (Bonvilliani y otros 2010: 10).

Según un miembro del Frente [entrevista personal, octubre 2018] la militancia es el "motor para visibilizar y dar fuerza a la cultura, para poner en crisis la gestión de Vidal y Macri”. Un militante manifestó [entrevista personal, 2018] "la mayoría somos de la gestión [municipal], tenemos las herramientas para transformar la realidad”; y en el programa radial del Frente [Radio Cítrica, 02/07/2018] se expresó concebir "la política como herramienta de transformación social" y al arte como la forma de impulsarla e impactar en la sociedad. Basándome en la observación de las prácticas colectivas del Frente, advierto que en sus intervenciones se postula al arte y la cultura como estrategia para la transformación social de desiguales sociedades (Infantino 2019a). Propuestas centradas en el paradigma de arte y transformación social "proponen el arte para transformar inequidades -de acceso y participación en la cultura y/o de oportunidades de formación artística-, para promover cambios -ya sea personales o grupales-, para luchar por un desarrollo cultural más equitativo" (Infantino 2019b: 36). Infantino (2019b) ha evidenciado el modo en el que al instalarse la cultura como recurso (Yúdice 2002) su movilización "se convierte 
en arena de disputa que pugna por definir los usos legítimos de ese recurso" (Infantino 2019b: 54).

Según García Canclini (1987: 26), las políticas culturales son el conjunto de intervenciones que realiza "el Estado, las instituciones civiles y los grupos comunitarios organizados a fin de orientar el desarrollo simbólico, satisfacer las necesidades culturales de la población, y obtener consenso para un tipo de orden o de transformación social”. En su producción intervienen diversos sectores y actores que apelan a la cultura desde diferentes sentidos y desiguales condiciones de poder (Crespo, Morel y Ondelj 2015). Advierto en el Frente una disputa entre dos modelos de política cultural, uno anclado en la democracia participativa y otro de carácter neoliberal.

En el Frente hay integrantes sin experiencia previa de militancia que se han acercado por el interés artístico y por oponerse al macrismo. Sin embargo, la mayoría de sus militantes -jóvenes y artistas- ocupan un puesto laboral en la Dirección de Ciudadanía Cultural. ${ }^{11}$ Incluso varias personas los/las reconocen como "los chicos de Cultura" [nota de campo, 12/08/2019]. ${ }^{12}$ Propongo pensar al Frente como una forma de "militancia de la gestión" (Vázquez 2014), dicho concepto refiere a "experiencias en las cuales las causas por las que se participa, y la manera de hacerlo, poseen estrecha vinculación con la dependencia estatal -e incluso con el área- en la que sus miembros se desempeñan laboralmente" (ídem: 75). Asumo que la condición de trabajadores/as municipales es central para comprender la creación del Frente, porque militan apoyando el gobierno local y porque las redes laborales en el Estado explican los vínculos políticos que tejen entre ellos/as.

La relación entre trabajo estatal y militancia es tensionada por algunos/as empleados/as municipales que no militan ni asumen una posición político/ideológica, pero que en ciertas ocasiones son llevados/as a marchar con el Frente. Mediante charlas informales, me han comentado que por ser empleados/as municipales se les pide que participen sin tener en cuenta la voluntad o la afinidad ideológica -pese a lo dicho manifestaron compartir con el Frente el rechazo hacía medidas y gestiones neoliberales-. Este doble posicionamiento, en el caso de ciertos/as habitantes del partido (que simpatizan o no ideológicamente con la gestión) es interpretado como condición para obtener beneficios o recursos municipales. ${ }^{13}$ En el caso de los/las integrantes del Frente que trabajan en el área estatal, algunos/as marcaron una tensión en el doble posicionamiento, así un miembro expresó [entrevista personal, agosto 2019]: "Por un lado a la gestión le dedicamos muchísimo tiempo, cuerpo y conocimiento, pero militar militamos en el Frente Cultural, en nuestra organización política”. Pese a lo dicho, asumen que la incumbencia en ambas áreas es central, de este modo, algunos/as expresaron [entrevistas personales, agosto 2019]: "no se puede gestionar sin ser parte de la política [...] Por otro lado si se puede hacer política sin estar adentro de la gestión, pero al estar adentro tenes más posibilidad de gestionar recursos, de conducir"; "milito la posibilidad de transformar la realidad y la posibilidad que me da la gestión para transformarla”.

Como se vio, el proceso electoral es central para analizar el accionar del Frente. Entre sus activistas se configuró un repertorio de acciones militantes vinculado a "militar" la campaña,

11 Dependiente de la Secretaria de Cultura de la Municipalidad de Avellaneda.

12 Así se refirió una vecina al comentar que asistió al Centro Cultural Alas del Sur.

13 Por ejemplo, en el caso de la actividad musical, hay una tendencia entre los músicos a justificar la actuación en eventos municipales del colectivo UMA por la participación/militancia política que asumen. 
participando mediante la intervención del espacio público -fomentando la crítica hacía la situación actual, reivindicando las políticas y medidas kirchneristas y denunciando las neoliberales del macrismo- y acompañando en la campaña electoral para obtener participación y votos. El colectivo asume una posición política que tiene que ver, para muchos de sus integrantes, con el lugar laboral que ocupan en el Estado. Entonces, en la experiencia activista del Frente "el Estado se configura como núcleo de sentido que se articula de diferentes maneras con la militancia, caracterizada como una militancia por, para o desde el Estado" (Vázquez 2015b: 14).

Es interesante la propuesta de Vommaro (2015), que sostiene que hay prácticas culturales juveniles que expresan politicidad, dado que contestan al orden vigente e intervienen en el espacio público; en este sentido, el autor concibe la política como una producción relacional y dinámica, en proceso. A su vez, para Vázquez, el activismo está asociado "a una serie de razones por las cuales en determinado contexto sociopolítico es posible militar" (2015a: 425). De este modo, lo que explica la construcción del Frente es la elaboración de una causa colectiva -"poner en crisis las gestiones de cambiemos"- que hace a la producción de interpretaciones comunes y de aspectos por los que, en estos momentos, vale la pena luchar, comprometerse, en un Frente Cultural.

Dado que estos/as militantes conciben al arte como una herramienta para la lucha política, buscan trabajar desde lo simbólico, expresivo y político para "sensibilizar y concientizar políticamente al pueblo" [documento oficial]; y por eso realizan acciones e intervenciones públicas, para denunciar la crisis y hacer palpable la inconformidad ante las gestiones macristas -enfrentando y criticando, así, sus políticas neoliberales, y promoviendo la concientización y participación ciudadana- ${ }^{14}$ Propongo, entonces, pensar el activismo político del Frente como performance, entendida como interpretación y posicionamiento sobre el contexto de crisis social, desde el cual se busca impulsar la reflexión crítica y el posicionamiento social frente al macrismo, en pos de transformar la realidad. En este sentido, la actuación del Frente puede entenderse en términos de "movilización" ya que comporta un trabajo de formación política y sus formas de acción se orientan a la transformación (Trom 2008). Pero "la movilización no sólo es pensada como modo de cuestionamiento social sino también como la condición de posibilidad para promover cambios" (Natalucci 2014: 159).

Como veremos, para realizar la acción colectiva en el espacio público los/las integrantes del Frente elaboran argumentos, ponen en escena conflictos, actúan e interpretan una dramatización, una performance, donde la teatralidad es central para generar impacto y movilización. En estas intervenciones el gobierno nacional y provincial, el neoliberalismo y el Fondo Monetario Internacional $(\mathrm{FMI})^{15}$ son presentados como los enemigos de la patria, los responsables de la crisis -y convertidos en problema público-. De este modo, quienes integran el Frente se presentan en el espacio público y virtual, denuncian al macrismo y se dirigen al público tratando de fomentar la crítica hacía dichas gestiones. Se observa como las operaciones de enmarcamiento definen una situación como problemática e imaginan los medios de resolverla, movilizan los actores en un colectivo y justifican su oposición a un adversario (Cefaï 2008).

14 Se destaca el "Primer Encuentro de trabajadorxs de la cultura" -realizado en junio de 2018-, donde se intentó denunciar la situación de ajuste y hacer palpable el rol transformador del arte y la cultura.

15 Organización financiera internacional con sede en Washington, Estados Unidos. Brinda asistencia financiera a los países miembros a cambio de imponer políticas que apuntan a reducir el gasto público, condicionando, de esta manera, la política nacional de los Estados. 
Turner (1982) entiende la performance como acto creativo de retrospección donde el significado se escribe a los eventos y fragmentos de la experiencia. Las performances serían prácticas vinculadas a experiencias de la comunidad, las cuales moldean las experiencias y generan vivencias. En este sentido, a través de sus intervenciones, el Frente "habla de algo", retrata conflictos causados por las medidas del macrismo (que considera como neoliberales) y evidencia la situación actual de crisis (en términos de drama social). Siguiendo a Avenburg (2012), y a los enfoques en los que se centra, ${ }^{16}$ propongo abordar a la performance como formas de expresar, interpretar, recrear y crear experiencias. Las acciones performativas del Frente recrean ideas, valores, sentidos y significados del colectivo, que pueden transmitirse e incorporarse en los actores, dado que al ser "actuadas", "actúan” en ellos mismos, es decir, los modifica.

Los motivos por los cuales el Frente llama a la movilización y busca promover -y otorgar sentido a- la participación política y el compromiso, tienen que ver con la crisis social que consideran producto de las políticas neoliberales de cambiemos. En este sentido, la suba de tarifas, el ajuste presupuestario y la crisis social son temas en torno a los cuales las situaciones son problematizadas, las reivindicaciones definidas y los programas de acción diseñados -y son las cuestiones que movilizan adhesiones militantes-. Como se verá a continuación, pude observar que los motivos que el Frente expone en sus intervenciones son aceptados, dado que las personas (en la vía pública y mediante redes sociales) demuestran apoyo en el accionar, los motivos y las reivindicaciones de los/las militantes. En general, los/las vecinos/vecinas que se suman a participar en las intervenciones, como quienes transitan por la vía pública, adhieren a las demandas del Frente y expresan coincidir en el malestar hacia la situación del país -criticando las medidas del gobierno provincial y nacional-.

\section{LAS INTERVENCIONES ARTÍSTICO-CULTURALES EN EL ESPACIO PÚBLICO}

El activismo del Frente se centra en la presencia e intervención artística del espacio público como modalidad de protesta y movilización, legitimada por la gestión municipal que llama a ocupar las calles como espacio de encuentro, denuncia y resistencia. ${ }^{17}$ Esto muestra cómo el Estado municipal impulsa y propicia el desarrollo de estas acciones culturales desde un Frente que no es estatal en términos estrictos pero que reproduce principios de visión y acción del gobierno local. El Frente despliega acciones e intervenciones colectivas en el territorio, mediante puestas en escenas, con el fin de denunciar la crisis, criticar y discutir públicamente las políticas y medidas del macrismo, generando adhesión y reclutamiento militante. En estas intervenciones se usan imágenes y símbolos patrios como la bandera argentina con la inscripción: "Vidal para la mano. Basta de recorte en cultura y educación", ${ }^{18}$ y la imagen que oficia de logo del Frente (la cara de María Remedios del Valle) pintado con stencils.

16 A saber: Bruner 1986, García 2005, Turner 1982, 1985, 1986 y 1987.

17 El intendente en sus actos llama a la movilización y participación como modo de lucha contra el ajuste y la crisis, lo cual se concibe como una oportunidad para militar [notas de campo, 2018].

18 En respuesta a las medidas de recorte en educación y cultura implementadas por las gestiones de cambiemos en general, y en particular ante las resoluciones $\mathrm{N}^{\circ}$ 2017-2393-E, 2017-2394-E, 2017-2395-E y 2018-29, de la Dirección General de Cultura y Educación de la Provincia de Buenos Aires, que dispusieron la disminución del aporte estatal provincial en un 50\% a partir del ciclo lectivo 2018, correspondiente a los institutos de enseñanza artística/cultural de Avellaneda. Ante tales medidas, el Honorable Concejo Deliberante de Avellaneda sancionó en mayo de 2018, la resolución $\mathrm{N}^{\circ} 1512$ donde se expresó repudio al recorte presupuestario y se exigió a la 
Los "semaforazos" fueron la forma de intervención del espacio público más usada por el colectivo para criticar y enfrentar el ajuste en cultura y educación. Durante 2018, se movilizaron estudiantes, docentes, integrantes del Frente y de la comunidad, quienes mediante carteles y pancartas ${ }^{19}$ exponían frases como: "Sin educación pública no hay futuro"; "Defendamos la educación pública"; "No al ajuste”; "El arte es lucha”; y dibujos de manos con lápices, y pinceles y tijeras con la inscripción "-100\%" (en referencia a la quita del subsidio a los Institutos Municipales de Arte, dispuestos por la gestión provincial). De este modo, mediante frases e imágenes las intervenciones buscaron interpelar a la ciudadanía y promover su participación.

En octubre de 2018 se realizó un "semaforazo" con el objetivo de denunciar que detrás del presupuesto 2019 estaba el FMI; para ello los/las militantes con vestimenta negra ocupaban la avenida en cada corte de semáforo y sostenían dos carteles, uno adherido a sus cuerpos con letras que formaban la palabra presupuesto y otro en sus manos con un signo de interrogación que al dar vuelta mostraba la sigla FMI con la cara de Christine Lagarde. ${ }^{20}$ Finalizada la intervención, los/las militantes confluyeron en el Centro Cultural Mercado, donde el intendente declaró la Emergencia Cultural. Pude observar que el Frente recurre a estrategias de "movilización de consenso" (Cefaï 2008), a saber: imágenes que remueven emociones, estereotipos populares y categorías del sentido común, que son bien recibidas y apoyadas por los/las transeúntes.

En noviembre de 2018, el Frente realizó un "semaforazo artístico" en contra de la Cumbre del G-20 a realizarse en Buenos Aires. En una avenida principal, integrantes del Frente sostuvieron una bandera con la inscripción "Malvenido G 20. Ayer encadenados, hoy endeudados". La letra G figuraba escrita con los signos que aluden a un gato -bigotes, orejas y cola- en referencia al popular apodo que se le asigna a Maurico Macri; y el número cero dibujado como el logo de canal 13 (miembro del Grupo Clarín). ${ }^{21}$ Los/las integrantes del Frente portaron vestimentas negras, máscaras, palos; mientras que un militante disfrazado de buitre circuló con movimientos bruscos. En estas intervenciones advierto una producción estetizada de la crisis, del macrismo, del neoliberalismo y del FMI (como causantes de la primera); estas cuestiones son expresadas artísticamente a través de una puesta en escena, así, circulan como imágenes produciendo relaciones y vínculos entre las personas.

Para analizar la actuación (performance) cultural en estas intervenciones artísticas, propongo abordar la manera colectiva en que son producidas por quienes integran el Frente. Siguiendo a Stoelje (Stoelje y Bauman 1988), considero a estas intervenciones como eventos donde se aprehende, representa y pone en escena una cultura. En este sentido, cada actuación, que se centra en un tema vinculado con la experiencia del grupo y con lo que se quiere expresar, es planeada, organizada e interpretada en un momento y lugar específico (ídem). Según expresó un integrante del Frente:

nos ponemos todos de acuerdo a la hora de hacer una actividad. En principio definimos cual va a ser el mensaje, eso es lo más importante, que mensaje queremos dar. Por ejemplo, cuando pasó lo de Cristine Lagarde con toda la movida del FMI, que se hizo la reunión del

Gobernadora de la Provincia la derogación de las Resoluciones que establecen dicho recorte. Finalmente, la justicia aceptó el amparo para que la Provincia restituya los fondos destinados a cultura.

19 Material elaborado en el Centro Cultural del Frente para usar durante las intervenciones. Es de destacar que

en el Centro Cultural se define la decoración, la narración y los personajes de las performances.

20 Directora gerente del Fondo Monetario Internacional.

21 Grupo empresario de medios de comunicación más grande de la Argentina. 
G20, nosotros creíamos que teníamos que dar un mensaje en contraposición a eso que estaba celebrando la derecha y un montón de personas porque sabíamos que nos iba a generar políticas de vaciamiento, de ajuste, etc. Entonces dijimos vamos a denunciar lo que está pasando con el G20. [Entrevista personal, agosto 2019]

Una vez definido el mensaje, las comisiones debaten sobre cómo abordarlo. ${ }^{22}$ En este caso, se resolvió confeccionar un buitre y usar distintos lenguajes artísticos (plástica, música, circo). Las tareas fueron divididas y cada comisión aportó desde su incumbencia: comunicación se ocupó del registro; logística consiguió y transportó los materiales; e intervención artística fabricó el buitre. De este modo, según un miembro del Frente [entrevista personal, agosto 2019]: "salimos a hacer una especie de escena lubre, medio de terror, denunciando al FMI, a Cristine Lagarde y el buitre diciendo: «nos van a carnear a todos como pueblo»". Observo que, la potencia de actuar en colectivo tiene que ver con lo que la actuación produce entre quienes integran el colectivo y entre estas personas y quienes por allí transitan, que reaccionan y se movilizan ante estas intervenciones.

Lo dicho se observa en las actividades que el Frente realizó a principios de 2019, las cuales se concentraron en los "ruidazos", una forma de protesta y/o movilización contra los "tarifazos". ${ }^{23}$ En una plaza los/las militantes sostuvieron carteles y pancartas con dibujos e inscripciones como: "no más aumentos"; "los tarifazos son un robo al pueblo"; "Así no se puede vivir"; "Macri y Vidal son hambre". Generaron ruido (con instrumentos musicales y objetos de cocina); cantaron contra Mauricio Macri; repartieron volantes convocando a la participación; ${ }^{24}$ y finalizada la actividad entonaron el himno nacional -lo que generó que personas desconocidas se unan en un canto-.

En los “ruidazos" un militante disfrazado de buitre y con una remera con la cara de Christine Lagarde y la inscripción FMI, invadió la calle moviendo sus alas en cada corte de semáforo. Así, mediante imagen, texto y una puesta en escena, la intervención expresó un conflicto puntual; el militante interpretó una dramatización y personificó teatralmente al fondo buitre, con la intención de movilizar y llamar a la participación. La intervención causó el efecto esperado ya que obtuvo el apoyo de vecinos, quienes se sumaron a participar en la intervención -algunos con cacerolas y cucharas- y de conductores que reaccionaron con "bocinazos". Advierto, entonces, que a través de estas imágenes, los/las integrantes del Frente se vinculan en sus experiencias culturales entre sí y con vecinos y transeúntes, y el lazo móvil que se conforma guarda relación con el conflicto que se quiere denunciar en cada oportunidad.

Pese a que estas intervenciones son realizadas por los/las integrantes del Frente Cultural y forman parte del repertorio de acciones militantes de la organización, cada vez que interviene en la vía publica el colectivo se presenta ante los vecinos como ciudadanos y no como artistas militantes -aun así, tal como ya se expresó, generalmente son reconocidos/as por vecinos/as

22 En el Frente existen grupos de trabajo o espacios de militancia. A saber: las comisiones de intervenciones artísticas -reúne a militantes dedicados a las performances-, las de comunicación -se ocupan de las redes sociales y el programa de radio-; las de logística, técnica, finanzas y gestión.

23 Coloquialmente, se denomina así al conjunto de medidas tomadas por la presidencia de Mauricio Macri para aumentar las tarifas de los servicios públicos, del sector energético y del transporte público. Las mismas generaron descontento popular, influyendo en el nivel de vida de amplios sectores de la población, lo cual derivó en manifestaciones y protestas en todo el país.

24 En una oportunidad solicité volantes para repartir durante una actividad. Pude vivenciar así la buena recepción y el apoyo que manifestaron los/las transeúntes hacía el accionar y la causa del Frente. 
como parte de la gestión, como: "los chicos de Cultura"-; mientras que cuando asisten a una actividad de gestión se presentan como una organización política. Ello se debe, tal como me informaron en varias oportunidades, a que buscan llegar a todos los vecinos, independientemente de la ideología política que asuman, lo cual se relaciona con el objetivo de generar adhesión y apoyo en contra del macrismo. Por lo dicho, es menester asumir que las comunidades y las identidades se instituyen mediante lazos dinámicos y flexibles producidos en las interrelaciones (Dipaola 2013).

E1 Frente participa en manifestaciones políticas ubicándose detrás de la agrupación del intendente local. Adelante se ubican los/las militantes que sostienen la bandera más grande con la inscripción: "Avellaneda cultura de la resistencia" y el logo del Frente. Otros/as militantes sostienen banderas con el logo del Frente y carteles -con dibujos y frases-, y el resto se encarga de la percusión. En este tipo de movilizaciones, las diferentes organizaciones son identificadas mediante banderas y logos que portan sus miembros, es así que estas imágenes son centrales en la organización general e imprescindibles en los lazos que establezcan los/las militantes de cada agrupación entre sí y con otras personas.

Desde mayo de 2019, las intervenciones del Frente se dirigieron hacía la campaña. "La Kermesse de las falsas promesas" fue una propuesta que revistió el formato de actividad lúdica y se realizó en plazas y mesas de campaña electoral del Frente de Todxs. La actividad constó de juegos que vinculaban las medidas y políticas de cambiemos con pobreza, desocupación, deuda e inflación. Según un integrante del Frente [entrevista personal, agosto 2019]: "pensamos un esquema distinto a lo que es la mesa tradicional de campaña con la boleta, con los volantes. Pensamos que a través de juegos podíamos interpelar a los vecinos de una manera diferente y con un mensaje político y partidario"; "todos los que pasan por la Kermese se llevan un libro. Les metemos la boleta adentro del libro”. Según expresaron integrantes del Frente -y observé personalmente- "la recepción de los vecinos fue buena y la gente se enganchó". En esta militancia preelectoral también fue central el plenario “Al frente con todxs' Avellaneda Cultura en Acción” que el Frente Cultural realizó y que contó con la presencia del intendente y la participación de colectivos culturales que se sumaron al Frente, y que apelaron a la unión, a la organización y al trabajo colectivo y militante para "hacerle frente al macrismo" y ganar las elecciones. El colectivo también se hizo presente en la "Presentación de la lista de candidatxs por el Frente de Todxs".

Advierto que las movilizaciones del Frente dinamizan diferentes luchas populares y conflictos sociales que se dirigen contra el macrismo. En estas experiencias orientadas hacia la campaña electoral de 2019, desde la gestión local y el Frente se insiste en la importancia de denunciar que "Vidal es lo mismo que Macri". El Frente busca captar, así, a los/las artistas no comprometidos, y con el advenimiento de las elecciones se intenta generar adhesión hacia el kirchnerismo por medio de la oposición hacía cambiemos. Es interesante vincular esto con la consolidada militancia kirchnerista con capacidad de movilizarse en defensa de lo que consideran un "gobierno popular" de la que hablan Pérez y Natalucci (2012). 


\section{LAS INTERVENCIONES ARTÍSTICO-CULTURALES EN EL ESPACIO VIRTUAL}

La difusión y convocatoria para las actividades e intervenciones se realiza mediante flyers y material audiovisual que los/las integrantes del Frente hacen circulan a través de redes sociales (grupos en WathsApp, Facebook e Instagram) y a los que le suman diferentes hasthags para lograr mayor impacto. En las redes se comparten imágenes (fotográficas o audiovisuales) que, por un lado, registran las jornadas de trabajo en el Centro Cultural donde se preparan y elaboran los materiales a usar en las intervenciones -como carteles, pancartas, banderas, disfraces, entre otros-. Así, el arte es definido a partir de las actividades colectivas que permiten la producción artística (Becker 2008), de este modo, se muestra la actividad artística como un aspecto central del colectivo. Por otro lado, también registran las intervenciones realizadas en la vía pública -con textos como: "hoy intervenimos las calles para demostrarles a los poderosos del mundo que acá hay un pueblo digno, que lucha y que no se deja pisotear"-. Se aprecia que el interés no solo está en realizar las intervenciones colectivas, sino que, además se prioriza el hecho de que sean vistas, incluso por quienes no han participado.

El primer video, ${ }^{25}$ que circuló promocionando el lanzamiento del Frente durante su primera actividad, reproduce imágenes de integrantes del Frente usando stencils para pintar el logo del colectivo en sus banderas y remeras. También se difundieron por redes sociales fotografías del evento con la consigna: ¡Súmate a militar! y el texto:

El Frente Cultural María Remedios del Valle surge ante la necesidad de una expresión política organizada (diversa, heterogénea, amplia) del campo de la cultura avellanedense frente al contexto actual de "urgencia nacional". Nos proponemos una organización política y cultural con una perspectiva nacional y popular, latino-americanista y feminista, que encuentre en el arte y en la cultura una herramienta de expresión y transformación social.

Pese a que, desde lo discursivo se apela al feminismo como una de las bandera de lucha del Frente y en las intervenciones también se usa lenguaje inclusivo, ${ }^{26}$ y se incorporan demandas como la legalización de la Interrupción Voluntaria del Embarazo; pude observar que en la práctica cotidiana, y tal como expresaron integrantes del Frente en reiteradas charlas informales, el feminismo queda relegado a un segundo plano, e incluso, a veces es desvalorizado como demanda popular por ciertos militantes del Frente. Advierto que los/las militantes del Frente se manifiestan públicamente mediante lenguaje inclusivo en las intervenciones que realizan aunque no ocurre lo mismo en el trato diario.

Los "ruidazos" se difundieron por redes sociales bajo los hasthag: \#VidalParaLaMano, \#MacriParaLaMano, y con el lema: "Decimos NO a los tarifazos del Gobierno Nacional y Provincial". En el fyer de difusión se presentó una imagen de los brazos de dos personas sosteniendo cacerolas, y la inscripción: "Ruidazo ¡Basta de tarifazos!”. Uno de los flyers fue acompañado con el texto: Ruidazo "hasta que Mauricio Macri abandone la Casa Rosada". Como toda organización política, el Frente busca promover el compromiso y la participación de sus

25 https://www.facebook.com/capitanadelvalle/videos/210214376457654/

26 Refiere al lenguaje no sexista y/o incluyente. En Argentina, la coyuntura actual marcada por el debate en torno a la legalización del aborto y las movilizaciones feministas atravesaron al lenguaje con la propuesta de usar la letra "e" (o, también, la letra " $\mathrm{x}$ ") como género no marcado, escapando de este modo al binarismo propio del idioma. El uso de este lenguaje es objeto de un debate que genera posturas enfrentadas, incluso la Real Academia Española expresó una postura reaccionaria ante el mismo. 
integrantes y de posibles adherentes $\mathrm{y} / \mathrm{o}$ militantes, $\mathrm{y}$ en este sentido, el recurso virtual asume un papel central. En los flyers se expresa: "la organización y el trabajo colectivo son necesarios para afrontar estos tiempos de individualismo neoliberal. No creemos en el sálvese quien pueda. Esta lucha no es solo un derecho, sino también una obligación para con nuestro pueblo"; y se usan lemas como: "Súmate. Quien no lucha, es cómplice". En este punto, Vommaro (2013) señala que las redes sociales, blogs y sitios web inciden en la constitución y ampliación de la militancia. En términos de Vázquez (2015a), el ciberactivismo se integra al repertorio de acciones militantes en estas organizaciones políticas, complementándolas: "así, la militancia barrial o estudiantil puede nutrirse de los recursos virtuales para favorecer la comunicación y la creación de redes, difundir noticias o información entre sus militantes o, incluso, como vía de contacto y reclutamiento de nuevos activistas" (ídem: 409).

La importancia de las redes sociales es vital para difundir las actividades del colectivo, para facilitar la comunicación entre sus integrantes, para generar convocatoria y adhesión; y, también es vital para postular, distinguir y oponer dos proyectos políticos. Por un lado, el gobierno nacional y provincial es estigmatizado por sus políticas de ajuste y desfinanciación -y presentado como neoliberal-; y por el otro, la gestión municipal es exhibida como un proyecto que promueve la participación e inclusión social y fomenta el arte, la educación y la cultura. Entonces, a través de flyers que circulan por redes sociales, el Frente celebra actividades, programas o proyectos municipales destinados a la cultura, el arte o la educación, y se posiciona contra las medidas de ajuste y desfinanciacion. En este aspecto, el programa de radio del Frente también cumple un papel central en términos de militancia comunicacional, dado que allí se busca visibilizar y legitimar acciones de la gestión municipal. Es de destacar que durante 2018 se hizo circular en las redes sociales, un video donde artistas y personalidades destacadas a nivel nacional expresaron apoyo hacia la lucha y el reclamo de los Institutos Artísticos de Avellaneda ante la quita de subsidios del gobierno provincial.

En el mismo sentido, a fin de distinguir y oponer esos dos proyectos políticos, los/las militantes del Frente crean y "viralizan" memes. ${ }^{27}$ Entre ellos se destacan dos, uno que circuló con la consigna: "Mira que distintxs somos", allí se observa cuatro imágenes. En la parte superior el flyer de Chano [músico argentino relacionado con adicciones y accidentes de tránsito] en el festival "Ciudad Emergente" organizado por el Gobierno de la Ciudad; y en la parte inferior el fyer del recital gratuito que Silvio Rodríguez dio en Avellaneda el 28 de octubre de 2018 con el lema "de la Habana a Avellaneda" junto con el slogan de la Municipalidad. Al lado de cada flyer se ubica la cara del rapero Drake, ${ }^{28}$ en una versión que representa una actitud de rechazo y desaprobación, y en otra que expresa aceptación a través de una sonrisa aprobatoria. Otro meme circuló con la consigna: "Veamos quién está detrás de este Presupuesto 2019. Ah, eres tú Christine!" y los hasthag \#PresupuestoCareta; \#PresupuestoDelAjuste. El meme reproduce una imagen de la serie animada Scooby Doo en dos cuadros. En el primero se observa al personaje de la serie intentando descubrir quién está detrás de una máscara con la frase presupuesto 2019. En el segundo cuadro, el personaje de la serie resuelve el enigma: quien estaba debajo de la máscara es Christine Lagarde. Así, en un contexto de definición del presupuesto 2019, el Frente expuso que el FMI es quien toma las decisiones. En las redes sociales circuló el texto: "Que el pueblo argentino sepa que este presupuesto 2019 es una careta, y que el FMI está detrás de esto".

27 Idea, concepto, situación, expresión o pensamiento manifestado en cualquier tipo de medio virtual, que se replica mediante Internet, de persona a persona, hasta alcanzar una amplia difusión.

28 Reconocido por una broma en las redes sociales que lo convirtió en meme. 
La "co-presencia” de la que habla Maffesoli (2005) refiere a que la vida social tiene que ver con "hacerse ver y ser visto para existir. Para decirlo de otro modo, no existimos sino en y por la mirada del otro" (ídem: 131). Maffesoli (2005) habla del mundo "imaginal" posmoderno, donde la imagen es el elemento central del lazo social. Esta omnipresencia de la imagen la encontramos en estas intervenciones, flyers y memes que se hacen circular en las redes sociales, y que parecen centrarse en la idea de que la acción/intervención política para existir debe hacerse ver.

Durante la campaña política, las intervenciones se difundieron con énfasis mediante las redes sociales. "La Kermesse de las falsas promesas" se difundió a través de videos, ${ }^{29}$ con música y estética circense (es de destacar que la actividad se trasladó de barrio en barrio todas las semanas). “¡Derribar lo que ya no va, apelar a la memoria y leer unos cuantos libros!”, “¡Acercate a jugar y, si ganas, te llevas un libro y algo más!", "Juga y llévate un libro de regalo" fueron los lemas con los que se difundió la actividad. En los videos y fotografías que se hicieron circular en las redes se nombraron los juegos que incluyó la actividad con una breve descripción. En referencia a la presentación de la "lista de candidatxs por el Frente de Todxs", observé que en las redes sociales se hicieron circular fotografías con el texto: "Acompañamos a nuestro compañero intendente en la presentación de la lista de candidates del \#FrenteDeTodos"; "La lista de unidad que garantiza derechos para todos y todas. En \#Avellaneda hay futuro. Desde \#Avellaneda vamos a trabajar para que el 10 de diciembre volvamos a tener esperanza y un Gobierno Nacional y Provincial que piense en los intereses de todes"; y los hashtag: \#EsConTodos \#EsConTodas.

El Frente, como lugar de circulación de las imágenes, produce un vínculo imaginal que se da a través de transitar sus intervenciones, de las relaciones que allí se producen en el flujo de esa experiencia, pero que también se da en la relación virtual, a través de redes sociales. Aquí se ve la eficacia que reviste el espacio inmaterial, según Maffesoli (2005): en la socialidad virtual de los grupos hay una búsqueda de unión mística, el deseo de entrar en contacto, aunque sea virtualmente. A partir de la categoría de hiperrealidad planteada por Baudrillard (1978), se puede abordar la importancia que el Frente le da a las imágenes. La hiperrealidad está ligada a lo virtual, la cultura estetiza la trama social y las relaciones sociales, haciendo que todo caiga bajo el signo de arte y se vuelve estético. En el Frente, la oposición hacía las gestiones macristas se estetiza y las fotografías/imágenes expuestas en las intervenciones y en las redes sociales se toman como si fuesen la realidad misma. De este modo, lo que se muestra en los videos que circulan por las redes sociales pasa a ser las intervenciones mismas.

\section{PALABRAS FINALES}

El Frente asume una acción colectiva e interviene, mediante manifestaciones artísticas, culturales y políticas, el espacio público -desde lo corporal y simbólico- y el espacio virtual; a fin de manifestar y movilizar contra las gestiones de cambiemos, con el propósito de generar adhesión política y reclutamiento militante a favor del kirchnerismo y en oposición cambiemos (en vista a las elecciones 2019). Este trabajo permite aportar a la reflexión sobre procesos de politización de la cultura -que tienen que ver con el rol transformador del arte y la construcción de lo político desde lo performativo, lo corporal, lo estético y lo virtual-, en torno a áreas y pro-

29 https://www.facebook.com/capitanadelvalle/videos/553478398391511/?q=La\%20Kermesse\%20de\%20 las\%20falsas\%20promesas\&epa=SEARCH_BOX 
gramas estatales que encuentran, en este caso, un elemento singular. La militancia en la gestión se asocia con áreas que articulan las causas militantes con el tipo de intervención (cultural) llevada adelante. En ese sentido, no se trata de ámbitos de recepción de militancias partidarias en el Estado, o viceversa, sino de la producción de causas militantes en, desde y para el Estado.

En el Frente se observan procesos de politización de la cultura que tienen que ver con la disputa política, la resistencia frente al neoliberalismo y la demanda de ampliación de derechos. A través de estas demandas colectivas y reivindicativas se lucha por "transformar" la situación de crisis social (por ejemplo, mediante acciones dirigidas a frenar el recorte presupuestario en materia de política cultural) y por incidir en un cambio de rumbo de estas medidas a partir de un cambio de gobierno. En el Frente, el arte y la cultura son un recurso de movilización social y política, cuyo objetivo es luchar por un modelo político que bregue por la ampliación de derechos, la expansión de políticas culturales, la participación ciudadana y -lo que se entiende por- justicia social. Más allá de la cuestión puntual de las elecciones, el Frente se propone el objetivo de lograr "la soberanía política, la justicia social, la independencia económica y la cultura propia de una comunidad organizada" [documento oficial]. Por lo dicho, el Frente puede ser leído como propuesta arte-transformadora (Infantino 2019b), dado su potencial disruptivo de imaginar y proponer nuevas configuraciones sociales de democracia participativa (opuestas a propuestas neoliberales).

La movilización social, política y cultural que asume el Frente Cultural entremezcla elementos como la territorialidad; la acción directa mediante prácticas políticas y artísticas-culturales que implican el uso del cuerpo y la intervención en el espacio público; y el uso de las nuevas formas y tecnologías de la comunicación y la información; con la particularidad de estar vinculado con la gestión municipal. Es de destacar la función de las imágenes -artísticas- como instrumento central de intervención púbica en la acción colectiva del Frente, la cual adquiere un sentido político dado que demuestra capacidad de transformar la realidad y de impactar e intervenir en el régimen político. A través de sus intervenciones artístico-culturales -públicas y políticas-, el colectivo -mediante el uso de imágenes y texto- produce lo real cómo imagen, produce la imagen de la crisis social y una narrativa que critica y protesta contra las medidas neoliberales del macrismo, a fin de influir en el resultado eleccionario.

Las performances del Frente se constituyen en la experiencia y en las formas de transitar. E1 Frente produce imágenes que circulan y producen al gobierno nacional y provincial, al neoliberalismo y al FMI como los enemigos de la patria, los responsables de la crisis; estas imágenes producen al colectivo como experiencia móvil, en circulación permanente, y en este proceso se gestan relaciones y vínculos flexibles -entre los/las militantes, y entre ellos/as y las personas con las que interactúan durante las intervenciones-. De esta manera, el Frente construye y es construido a través de las intervenciones, las redes sociales, las expresiones artísticas y/o culturales; y a través de los lazos sociales, las experiencias que por allí circulan, las formas de narrarla, de vivenciarla -con y entre otros- y de producir significados. 


\section{BibliografíA}

Avenburg, Karen. 2012. Recreando el pasado, posicionándose en el presente. Performance y experiencia en dos fiestas rituales de Iruya (Salta, Argentina). Tesis de Doctorado. Ciudad Autónoma de Buenos Aires: Universidad de Buenos Aires. Disponible en <http://repositorio.filo.uba. ar/handle/filodigital/1855>, consultado 2019-08-20.

Baudrillard, Jean. 1978. Cultura y simulacro. Barcelona: Kairós.

Becker, Howard. 2008. Los mundos del arte. Sociología del trabajo artístico. Bernal: Universidad Nacional de Quilmes Editorial.

Becker, Howard. 2009. Outsiders. Hacia una sociología de la desviación. Buenos Aires: Siglo XXI. Bonvillani, Andrea; Alicia Palermo; Melina Vázquez y Pablo Vommaro. 2010. "Del Cordobazo al kirchnerismo. Una lectura crítica acerca de los períodos, temáticas y perspectivas en los estudios sobre juventudes y participación política en la Argentina”, en Sara Alvarado y Pablo Vommaro, Jóvenes, cultura y politica en América Latina: algunos trayectos de sus relaciones, experiencias y lecturas (1960-2000). Rosario, Homo Sapiens Ediciones.

Bruner, Edward. 1986. "Experience and Its Expressions", en Victor Turner y Eward Bruner, The Anthropology of Experience. Introduction, pp. 3-30. Urbana y Chicago: University of Illinois Press.

Cefaï, Daniel. 2008. "Los marcos de la acción colectiva. Definiciones y problemas", en Natalucci Ana, La comunicación como riesgo: Sujetos, movimientos y memorias. Relatos del pasado y modos de confrontación contemporáneos, pp. 49-79. La Plata: Ediciones Al Margen.

Crespo, Carolina, Hernán Morel y Margarita Ondelj. 2015. “Introducción”, en Carolina Crespo, Hernán Morel y Margarita Ondeli, La politica cultural en debate. Diversidad, performance y patrimonio cultural. Buenos Aires: Fundación Ciccus.

Dipaola, Esteban. 2013. Comunidad impropia. Estéticas posmodernas del lazo social. Buenos Aires: Letra viva.

Ferreño, Laura y Giménez, María Laura. 2019. "Desafíos actuales de las políticas culturales. Análisis de caso en el Municipio de Avellaneda”. Cuadernos del Centro de Estudios en Diseño y Comunicación, 71: 33-49.

Fillieule, Olivier. 2015. "Propuestas para un análisis procesual del compromiso individual". Intersticios, 9 (2): 197-212.

García Canclini, Néstor. 1987. "Políticas Culturales y Crisis de desarrollo: un balance latinoamericano”, en Néstor García Canclini, Políticas Culturales en América Latina. México, Grijalbo.

Gupta, Akhil y Ferguson, James. 2008. "Más allá de la "cultura”: Espacio, identidad y las políticas de la diferencia". Antipoda, 7: 233-256.

Infantino, Julieta. 2019a. "Arte y Transformación social. El aporte de artistas (circenses) en el diseño de políticas culturales urbanas". Cuadernos del Centro de Estudios en Diseño y Comunicación, 71: 75-91.

Infantino, Julieta. 2019b. "Políticas culturales, arte y transformación social. Recorridos, usos y sentidos diversos en espacios de disputa”, en Julieta Infantino, Disputar la cultura. Arte y transformación social en la ciudad de Buenos Aires, pp. 19-63. Buenos Aires: RGC Ediciones.

Maffesoli, Michel. 2005. El instante eterno. Buenos Aires: Paidós.

Natalucci, Ana. 2014. "La cultura política en el kirchnerismo: dos hipótesis sobre la politización”. Sudamérica: Revista de Ciencias Sociales, 3: 155-171.

Pérez, German y Natalucci, Ana. 2012. "El kirchnerismo como problema sociológico", en German Pérez y Ana Natalucci, "Vamos las bandas" Organizaciones y militancia kirchnerista. Buenos Aires, Nueva Trilce. 
Saponara Spinetta, Valeria. 2018. "Articulación entre políticas culturales y un colectivo artístico (Avellaneda, 2018)". Terceras Jornadas de Investigación: Cuerpo, Arte y Comunicación, Universidad Nacional de la Plata.

Saponara Spinetta, Valeria. 2019. "Las practicas militantes del Frente Cultural de artistas "María Remedios del Valle" en la ciudad de Avellaneda durante el año 2018". II Jornadas de Sociología, Universidad Nacional de Mar del Plata.

Stoeltje Beverly y Bauman Richard. 1989. "The Semiotics of Folkloric Performance", en Thomas Sebeok y Jean Umiker Sebeok, The Semiotic Web. Berlin, De Gruyter Mouton.

Trom, Danny. 2008. "Gramática de la movilización y vocabularios de motivos", en Natalucci Ana, La comunicación como riesgo: Sujetos, movimientos y memorias. Relatos del pasado y modos de confrontación contemporáneos, pp. 21-48. La Plata: Al Margen.

Turner, Victor. 1982. From ritual to theatre. The human seriousness of play. Nueva

York: PAJ Publications.

Turner, Victor. 1985. "The Anthropology of Performance" y "Experience and Performance", en Victor Turner, On the Edge of the Bush. Anthropology as Experience. Pp. 177-204; 205-226. Tucson: The University of Arizona Press.

Turner, Victor. 1986. "Dewey, Dilthey, and Drama: An Essay in the Anthropology of

Experience”, en Victor Turner y Edward Bruner, The Anthropology of Experience, pp. 33-44. Urbana y Chicago: University of Illinois Press.

Turner, Victor. 1987. "Images and Reflections: Ritual, Drama, Carnival, Film, and Spectacle in Cultural Performance", "Rokujo's Jealousy: Liminality and the Performative Genres” y "Carnaval in Río: Dionysian Drama in an Industrializing Society", en The Anthropology of Performance, pp. 21-32; 99-122; 123-138. Nueva York: PAJ Publications.

Vázquez, Melina. 2014. "Militar la gestión: una aproximación a las relaciones entre activismo y trabajo en el Estado”. Apuntes. Revista de Ciencias Sociales, 74: 71-102.

Vázquez, Melina. 2015a. "Del que se vayan todos a militar por, para y desde el Estado. Desplazamientos y reconfiguraciones del activismo y las causas militantes luego de la crisis de 2001 en Argentina”, en José Manuel Valenzuela Arce, El sistema es antinosotros. Culturas, movimientos y resistencias juveniles. México: UNAM/COLEF/GEDISA.

Vázquez, Melina.2015b.Juventudes, políticas públicas y participación. Un estudio de las producciones socioestatales de juventud en la Argentina reciente. Buenos Aires: Grupo Editor Universitario.

Vommaro, Pablo. 2013. "Balance crítico y perspectivas acerca de los estudios sobre juventudes y participación política en la Argentina (1960-2012)". Sudamérica: Revista de Ciencias Sociales, 2: 91-130.

Vommaro, Pablo. 2015. Juventudes y politicas en la Argentina y en América Latina. Tendencias, conflictos y desafíos. Buenos Aires: Grupo Editor Universitario.

Yúdice, George. 2002. El recurso de la cultura. Usos de la cultura en la era global. Barcelona: Gedisa.

\section{ARt And Politics: The Public InTERVentions of the “María Remedios del VAlle" Cultural Front (AvelLanedA, 2018-2019)}

The "Maria Remedios del Valle" Cultural Front is a group of militant artists of the city of Avellaneda,
formed in 2018. The group presents itself as a support base for the Kirchnerist efforts in relation to
the 2019 elections and opposes the changes and its policies. The purpose of the article is to analyze the
collective and militant action that the Cultural Front assumes, focusing on the claims and the artis-
tic-cultural interventions - understood in terms of performance - that were performed in the public 
and virtual space, between June 2018 and August of 2019. The author interviewed militants, adherents of the Front and management workers and observed the activities of the collective, including its social networks. In the current context of social crisis, it is of interest to visualize the collective action of the actors towards the policies that affect them.

Keywords: collective action, militancy, public interventions, performance, artists

Data recibido: 2019-08-28

Data aceptado: 2020-01-22 